\title{
Effect of Chemically Treated Leather Shaving Addition on Characteristics and Microstructure of OPC Mortars
}

\author{
Daniel Veras Ribeiro ${ }^{\mathrm{a} *}$, Shi Yung Yuan ${ }^{\mathrm{b}}$, Marcio Raymundo Morelli ${ }^{\mathrm{b}}$ \\ ${ }^{a}$ Department of Materials Science and Technology, Federal University of Bahia, \\ Rua Aristides Novis, 2, Federação, CEP 40210-630, Salvador, BA, Brazil \\ ${ }^{b}$ Department of Materials Engineering, Federal University of São Carlos, \\ Rod. Washington Luis, Km 235, CEP 13565-905, São Carlos, SP, Brazil
}

Received: August 28, 2011; Revised: November 30, 2011

\begin{abstract}
The growing concern with environmental issues in tanneries and the search for a technological solution to their wastes are evaluated in this study. The leather shaving was chemically treated aiming the immobilization of the chromium ion on ordinary Portland cement (OPC) matrix. Cementitious mortars were obtained by adding different proportions of waste treated solutions ( 5 and $10 \%$ compared to the cement mass) and after 28 days, the samples were evaluated in relation to their physical properties, axial compressive strength and, for the most promising compositions, microstructural characterization analyses tests were realized. Results showed that the alternatives used for the pretreatment were effective for the leather shaving dissolution; but the results analysis describes little change in $\mathrm{pH}$ values when the treated waste is added in three different media. The best axial compressive strength after 28 days age were obtained by addition of diluted phosphoric acid solution at low concentration, although this addition minimize the Portlandite formation and favor the calcium phosphate formation.
\end{abstract}

Keywords: leather shaving, waste, mortar, Portland cement

\section{Introduction}

The Leather industry is responsible for a large generation of wastes during the skin tanning process to produce leather products to supply shoes, automotive and furniture markets. Brazil, according to the Center of Tannery Industries of Brazil (CICB), is the second largest producer of leather in the world and the fourth largest exporter of leather ${ }^{1}$.

Chromium sulfate is the most widely used reagent in mineral tanning process with a concentration in the tanning bath of roughly 1.5 to $5.0 \%$ of the total gross weight of salty skin. Environmental issues then become an important variable: although the used chromium in chrome tanning is in its trivalent form (less toxic than the hexavalent chromium, which is carcinogenic), wastes containing chromium are classified as "Class I" (hazardous) waste, according to NBR 10004/2004, and therefore they need treatment before disposal in landfills. The oxidation states of chromium can vary from -2 to +6 , but only the states 0 , +3 and +6 are relatively stable in the environment.

It is known that chromium in +6 oxidation state is extremely toxic comparing with chromium in +3 oxidation state. A simple transfer of electrons in change of oxidation implies a modification in its geometry, and the chromate anion $\left(\mathrm{CrO}_{4}\right)^{-2}$ has the same tetrahedral geometry of the sulfates and phosphate ions (with an easy penetration in cell membranes), contrary to $\mathrm{Cr}$ (III), with octahedral complex structure, difficult to penetrate the skin².

*e-mail: verasribeiro@ hotmail.com
The so called "leather shaving" waste, focus of this work, comes from the shaving process, which is carried out to achieve an even thickness throughout the skin/hide, and, because of its low specific weight, a large volume is accumulated in leather processing factories. One metric ton of wet salted hide yields $100 \mathrm{~kg}$ of this waste ${ }^{3}$.

Portland cement is commonly used in order to encapsulate wastes due to its low cost and wide application, in several areas. Among specific reasons why Portland cement processes are so important in this technology are: a) much more is known about the reactions of Portland cement in setting and hardening, and more recently, in fixation of metals; b) good data on modeling of environmental effects from the leaching of cement-based waste forms are available from the nuclear waste field ${ }^{4}$.

In recent studies, Nazari and Riahi ${ }^{10,11}$ observed that the partial replacement of cement by nano- $\mathrm{Cr}_{2} \mathrm{O}_{3}$ particles (up to 1-2\%) increases compressive strength and decreased percentage of water absorption of concrete specimens. However, the workability of concrete was reduced by adding $\mathrm{Cr}_{2} \mathrm{O}_{3}$ nanoparticles.

So in an attempt to inerted chromium present in the leather shavings waste in a cementitious matrix, a pretreatment was conducted so that all organic material from the waste decomposes in different chemicals products with different $\mathrm{pH}$ values. In this work, the influence of the addition of these solutions in the microstructure and basic properties of Portland cement was studied. 


\section{Materials and Methods}

\subsection{Materials}

The mortars were prepared with Portland cement 32.5, which is equivalent to ASTM C 596 (Pozzolan-modified Portland cement). The fine aggregate was natural siliceous sand. The leather shaving was collected manually and randomly from disposal area of a leather gloves scrapings manufacturing in Bocaina city, São Paulo (Brazil) and preserved in plastic bags to protect from the heat incidence.

The acid used for pretreatment of leather shaving containing chromium was the phosphoric acid (concentration of $85 \% \mathrm{P}_{2} \mathrm{O}_{5}, \mathrm{pH}=1.5$ and density $\left.1.65 \mathrm{~g} . \mathrm{cm}^{-3}\right)$. The base used was the caustic soda in flakes - $\mathrm{NaOH}$ (Manufacturer: Sansão) at concentration of $75 \%$, commercially found in construction materials stores.

\subsection{Methods}

Experimental development followed a series of steps that can be described by the chemical treatment of the leather shaving, mortars preparation and samples characterization after 28 days of age.

A waste pretreatment was done in order to break the protein chain, which is the organic matter that basically composes the leather shaving. The pretreatment was performed before adding the solid waste (leather shaving) in the mortars, to prevent the decomposition of organic matter over time (aging) that can lead to the formation of large voids in the Portland cement matrix, and significantly affect its mechanical strength.

The leather shaving pretreatment was executed in three distinct ways: acid, basic and neutral. In the first one, the chemical solution was used to break the proteins chains. The solutions were prepared by leather shaving adding in phosphoric acid 85 wt.(\%) concentration in different proportions, i.e. 1:2, 1:3, 1:4, 1:5, 1:6, 1:12.

The basic chemical solution (concentration $75 \%$ ) was prepared adding caustic soda flakes in water and presenting basic $\mathrm{pH}$. The proportions used were the same to acid solutions i.e. 1:2 1:3, 1:4, 1:5, 1:6, 1:12. The chemical solution (water $+\mathrm{NaOH}$ ) has been prepared using a beaker, and the waste was added slowly followed by raising the temperature to about $70-80{ }^{\circ} \mathrm{C}$, and constant shaking. The solution containing leather shaving treated in basic medium had dark greenish color and characteristic leather odor, but with more intensity when compared to smell of waste treated in acid solution. The preparation time and the viscosity of treated waste solutions in alkaline conditions showed the same behavior as in an acid medium.

With the solutions containing waste treated in acidic and basic mediums, a third solution was prepared. The acidic and basic solutions were mixed in equal amounts to obtain a neutral solution. The solutions were neutralized in proportion $1: 6$ and $1: 12$, because these proportions are technically and economically interesting.

The mortar formulation used as reference was prepared by using the 1.0:3.0:0.50 (cement:sand:water) weight ratio. Different acidic, basic and neutral solutions were added in different proportions of treated waste in 5 and 10 wt.(\%). Cylindrical specimens of $50 \mathrm{~mm}$ in length and $30 \mathrm{~mm}$ in diameter were used to determine the mechanical strength, $\mathrm{pH}$, apparent porosity and density.

The values of axial compression correspond to the average of 5 (five) values for each composition, and were obtained with an Instron 5500R universal testing machine and a load of $1.5 \mathrm{~mm} / \mathrm{min}$. The values that differed by more than $5 \%$ from the average were discarded and were substituted for the results of new samples. The $\mathrm{pH}$ was evaluated by using a pen type pH Meter NA 2000, Microprocessado.

The apparent porosity and density were verified using the technique based on the Archimedes principle. The samples were weighed in the dried condition $\left(\mathrm{M}_{\mathrm{d}}\right)$. They were then left immersed in water for 24 hours until they became fully saturated, after which the immersed mass $\left(\mathrm{M}_{\mathrm{i}}\right)$ and the wet mass $\left(\mathrm{M}_{\mathrm{w}}\right)$ were determined. Thus, the apparent porosity $\left(\mathrm{P}_{\mathrm{A}}\right)$ and the apparent density $\left(\mathrm{D}_{\mathrm{A}}\right)$ were calculated according to Equations 1 and 2, respectively.

$\% \mathrm{P}_{\mathrm{A}}=100 \times\left(\mathrm{M}_{\mathrm{w}}-\mathrm{M}_{\mathrm{d}}\right) /\left(\mathrm{M}_{\mathrm{w}}-\mathrm{M}_{\mathrm{i}}\right)$

$D_{A}=\rho_{L} \times\left(M_{d}\right) /\left(M_{w}-M_{i}\right)$

where $\rho_{L}$ is the liquid density (in this in case, water, $\rho_{L}=1.0 \mathrm{~g} \cdot \mathrm{cm}^{-3}$ at $25^{\circ} \mathrm{C}$ ).

Besides the physical characterization of samples, the microstructural characterization via scanning electron microscopy (SEM) was also performed. In this work, a thin gold layer for coating was used, which served as a means of conducting electrons. The samples were analyzed in a scanning electron microscope Zeiss DSM 940-A. A $25 \mathrm{kV}$ voltage and $15 \mathrm{~mm}$ working distance were used.

\section{Results and Discussion}

\subsection{Raw materials characterization}

The used Portland cement (32.5) has a specific surface area of $0.93 \mathrm{~m}^{2} \cdot \mathrm{g}^{-1}$ and its specific gravity is $3.11 \mathrm{~kg} \cdot \mathrm{dm}^{-3}$. The sand has a specific surface area of $0.68 \mathrm{~m}^{2} \cdot \mathrm{g}^{-1}$ and its specific gravity is $2.70 \mathrm{~kg} \cdot \mathrm{dm}^{-3}$.

The leather shaving used in this work was investigated by Tachard $^{2}$, who observed some structural and physical characteristics: apparent density of $0.25 \mathrm{~g} . \mathrm{cm}^{-3}$, the moisture content is around 44.5 wt. $(\%)$ and loss on ignition of 94.8 wt.(\%). Fibrous structure aspects were observed from scanning electron microscopy, in micrographs shown in Figure 1.

A large percentage of mass lost on ignition (94.8\%) refers to organic material (protein fibers) that evaporates during the calcination and leaves a small amount of ash (5.2\%). Figure 2 shows the main crystalline phase detected by X-ray diffraction (XRD) to resulting ash from the loss on ignition test. The peaks concern to $\mathrm{Cr}_{2} \mathrm{O}_{3}$ arising from the chromium oxidation that is the main inorganic component present in this material.

Among the inorganic elements detected, the chlorine $(43 \%)$, chromium $(29 \%)$, sodium $(18 \%)$ and traces of aluminum and silicon were observed. These elements were detected due to the large amount of inputs used in the leather treatment. According to Brazilian standard NBR 10,004, the chromium content classifies this waste as hazardous. So the 


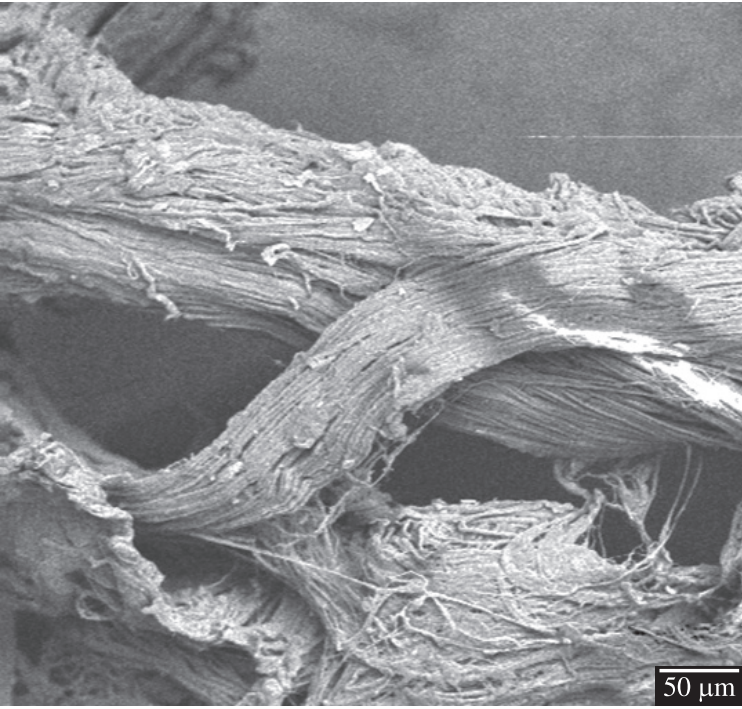

(a)

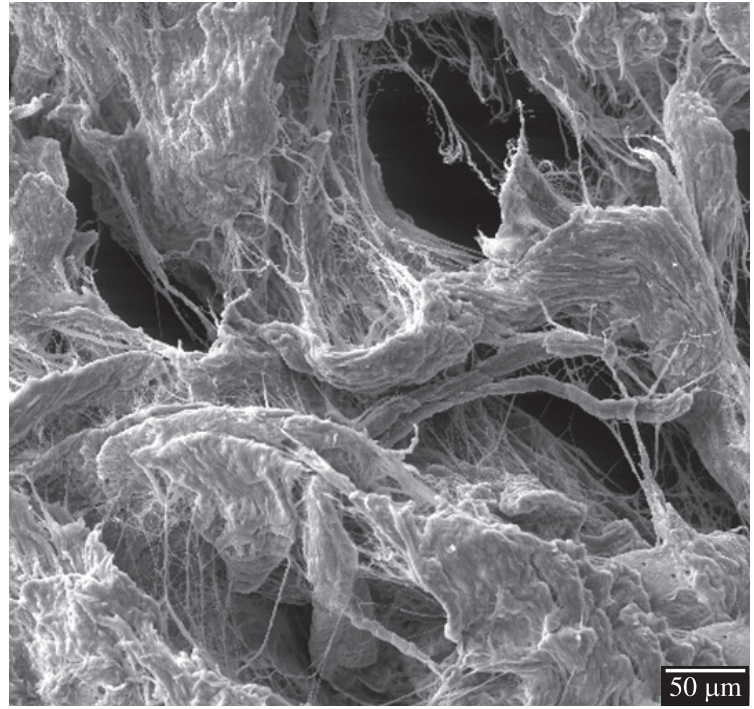

(b)

Figure 1. SEM micrographs of leather shaving, in two distinct regions.

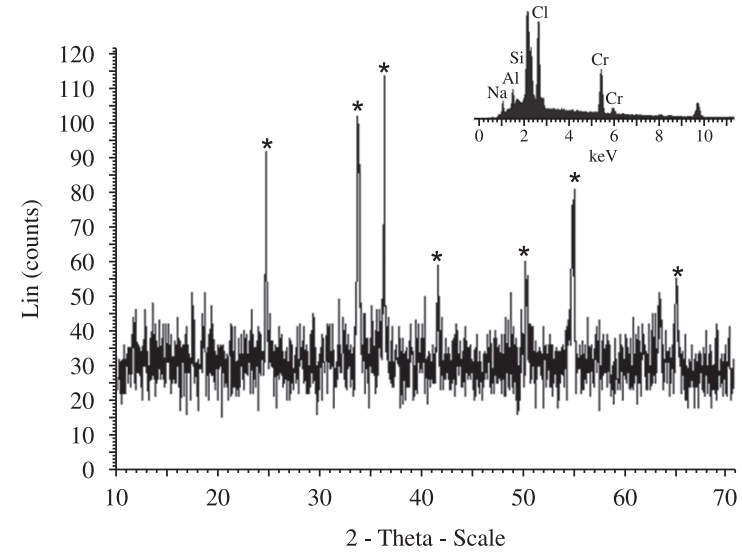

Figure 2. X-ray diffraction (XRD) pattern of leather shaving. The peaks marked with asterisks refer to $\mathrm{Cr}_{2} \mathrm{O}_{3}$.

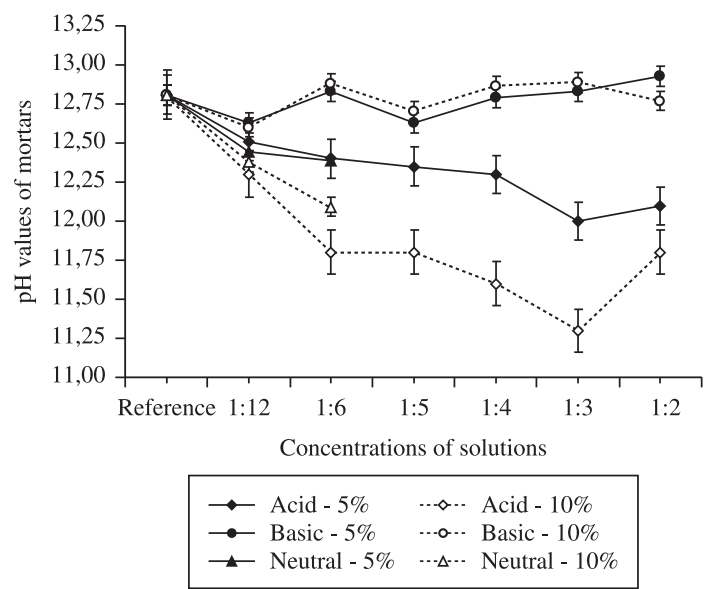

Figure 3. $\mathrm{pH}$ variation of mortars with leather shaving addition in different media.

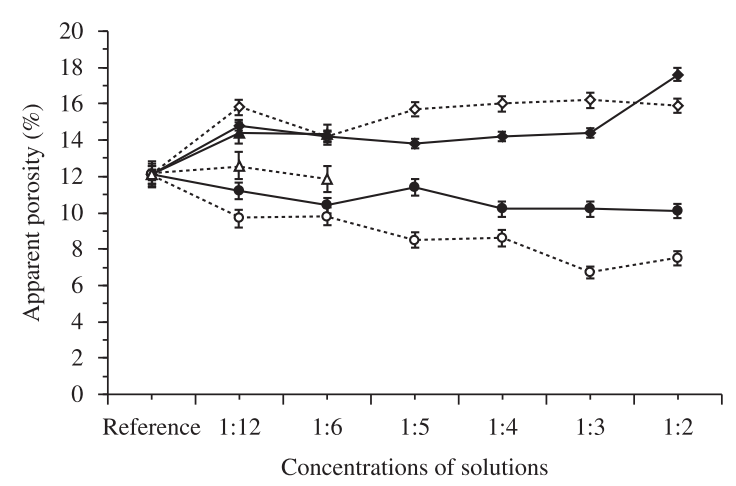

(a)

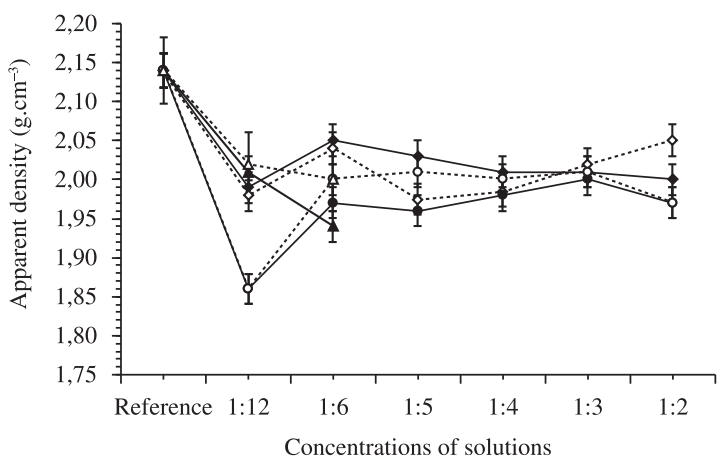

(b)

$\begin{array}{lll}\longrightarrow \text { Acid }-5 \% & \multimap & \text { Acid }-10 \% \\ \longrightarrow \text { Basic }-5 \% & \multimap & \text { Basic }-10 \% \\ \longrightarrow \text { Neutral }-5 \% & \rightarrow & \text { Neutral }-10 \%\end{array}$

Figure 4. a) Apparent porosity; and b) apparent density of Portland cement mortars containing leather shaving treated in acid, basic and neutral solutions, as a function of the solutions concentrations. 
chromium content in leather shaving was more precisely quantified by atomic absorption and the value obtained was 30.034 g. $\mathrm{kg}^{-1}$ on dry basis or $3 \%$ by mass, which is compatible with the values reported in the literature ${ }^{5}$.

\subsection{Mortar $p H$ variation}

Aiming to incorporate a significant amount of waste treated to cement matrix, 5 and $10 \mathrm{wt} .(\%)$ were added from the cement mass. The $\mathrm{pH}$ of the mortars obtained with the addition of this waste at different levels was then evaluated (Figure 3).

The results analysis describes little change in $\mathrm{pH}$ values when the treated waste is added in three different media. This small variation, presented in Figure 3, occurs due to the quantities of waste solution used (5 and $10 \mathrm{wt} .(\%)$ ) not being sufficiently high to cause a significant change in $\mathrm{pH}$ matrix, which displays a very basic character.

\subsection{Apparent porosity and apparent density}

It may be noted that there was a slight increase in the apparent porosity of mortars containing waste treated

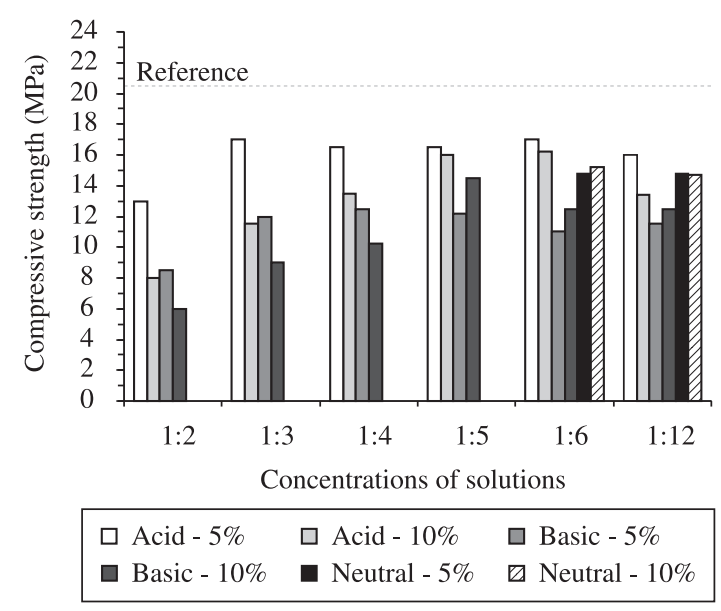

Figure 5. Axial compressive strength of Portland cement mortars containing leather shaving treated in acid, basic and neutral solutions, as a function of the solutions concentrations. in acidic and neutral media in all proportions (solution concentration and amount added), compared to the reference sample. The pretreatment of leather shaving on these media breaks the organic chains (protein dissolution) which, it may be randomly distributed in the matrix, probably interfered in the particle packing during the specimens molding and in the reactions of cement hydration during curing.

For the mortars prepared with the addition of waste treated in basic medium, the behavior was in inverse relation. The higher base/waste ratio used, the lower the apparent porosity (Figure 4a). This result can be explained by the fact that even with the protein fibers breakdown, the basic medium gave better particle packing due to the dispersant cations effect (deflocculation). More concentrated solution of waste treated in basic solution and greater amount added (10 wt. (\%)) represents lower apparent porosity obtained.

By the same procedure used for determining the apparent porosity (standard NBR 9778), the apparent density after 28 days was obtained, as shown in Figure 4 b. All samples showed a lower apparent density compared with the reference samples (without residue), showing that there is a strong contribution of organic material to the cement matrix density. About 95 wt. (\%) of leather shaving is formed by collagen fiber (dissolved), and the collagen fiber density is only $0.25 \mathrm{~g} . \mathrm{cm}^{-3}$.

\subsection{Compressive strength}

Mortar specimens were tested by compressive strength at 28 days age in order to study the effect of treated waste addition. The results are presented in Figure 5 and the average of obtained results from the five samples for each composition show that were little changed. The values that differed by more than $5 \%$ from the average were discarded and were substituted for the results of new samples.

The mechanical strength depends on the amount of $\mathrm{Cr}$ (VI) added to the system. To greater amount of Cr (VI) added, the material strength is lower ${ }^{6}$. But the Palomo ${ }^{7}$ study shows that the mechanical strength increases with increasing addition of $\mathrm{Cr}(\mathrm{VI})$, forming $\mathrm{CaCrO}_{4}$. A search using tannery sludge containing trivalent and hexavalent cromium revealed that the mechanical strength decreases, increasing the sludge amount added and that the addition of additives such as sand and fly ash increases the mechanical strength ${ }^{8}$.

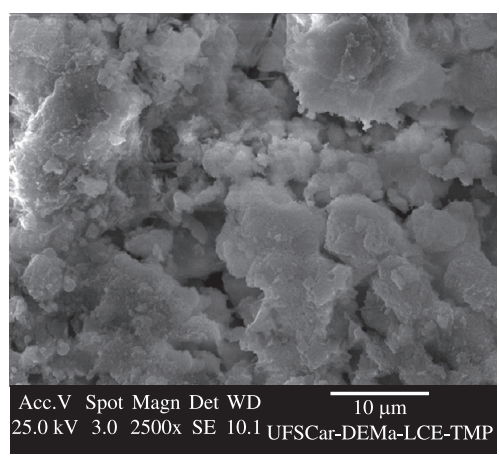

(a)

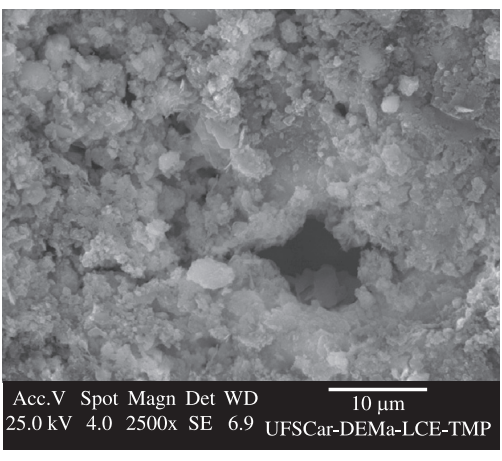

(b)

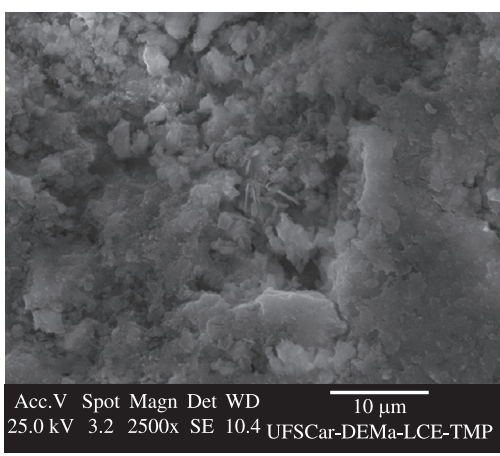

(c)

Figure 6. SEM micrographs of fracture surface region of Portland cement mortars containing $10 \mathrm{wt} .(\%)$ leather shaving treated in a) acid; b) basic; and c) neutral solutions. Concentration 1:6 (reagent:water). 
Tachard ${ }^{2}$ used leather shaving treated in acid medium and observed that the mechanical strength decreased due to the delay in setting time caused by acidic pretreatment solution. The difference in strength between the samples containing waste and the standard sample was slowly decreasing over time due to the cement hydration process. Similar behavior was observed in this study.

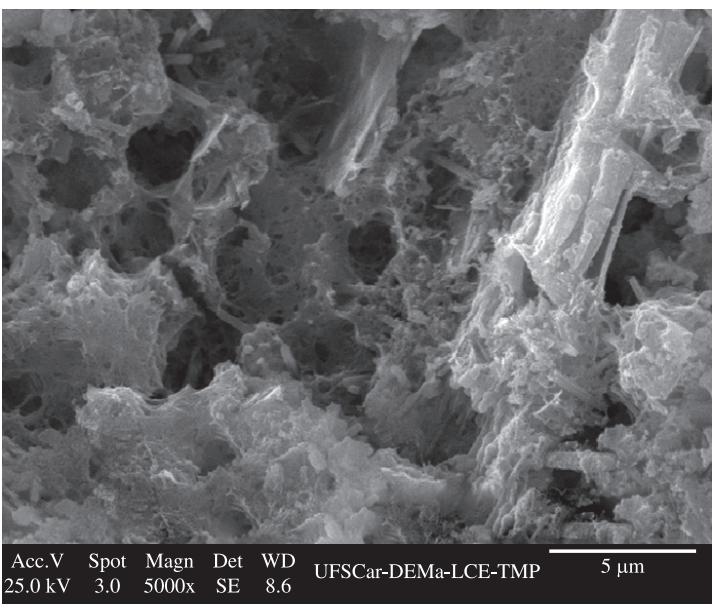

(a)

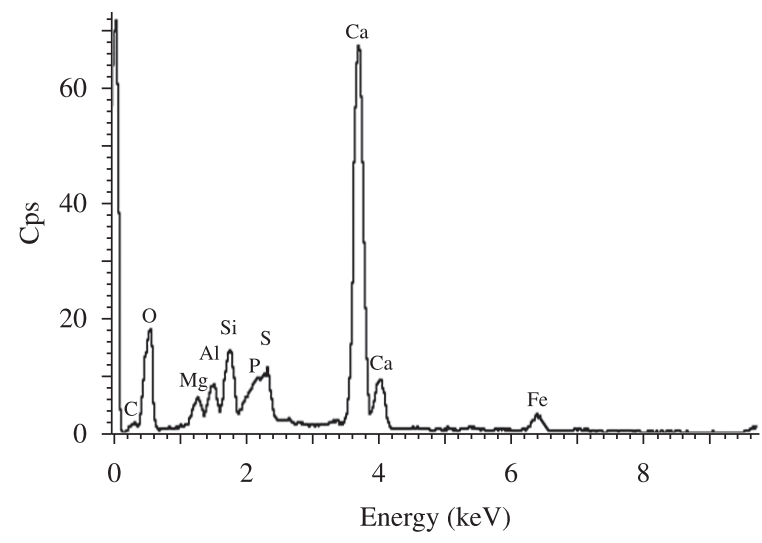

(b)

Figure 7. SEM micrographs and EDS of fracture surface region of Portland cement mortars containing $10 \mathrm{wt} .(\%)$ leather shaving treated in acid medium concentration 1:6 (reagent:water). a) Fibrous C-S-H phase and ettringite crystals; and b) microanalysis.

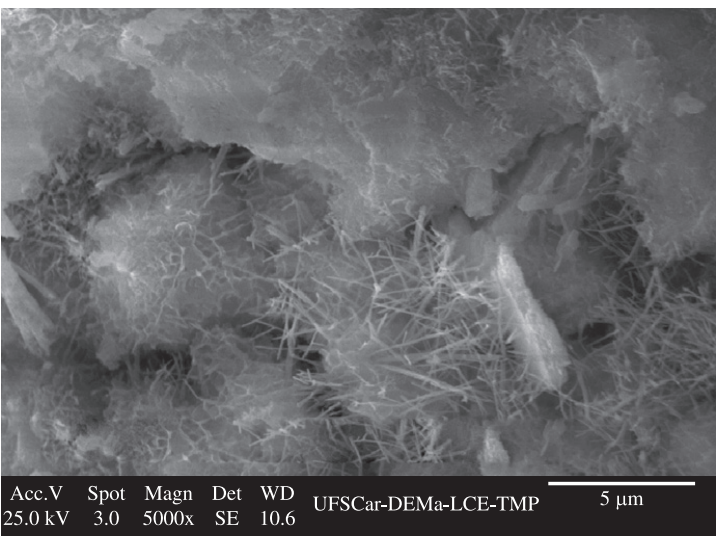

(a)

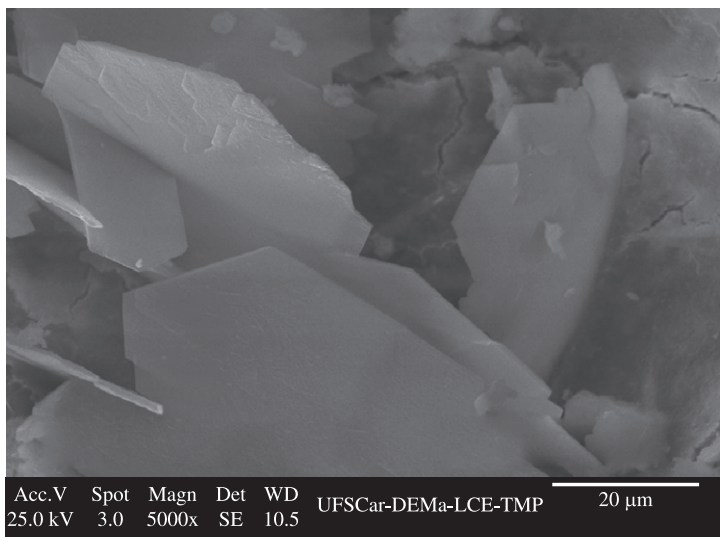

(c)

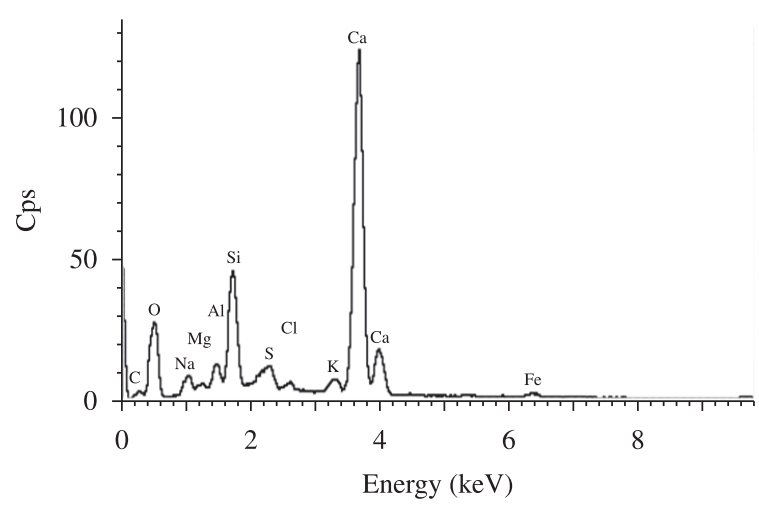

(b)

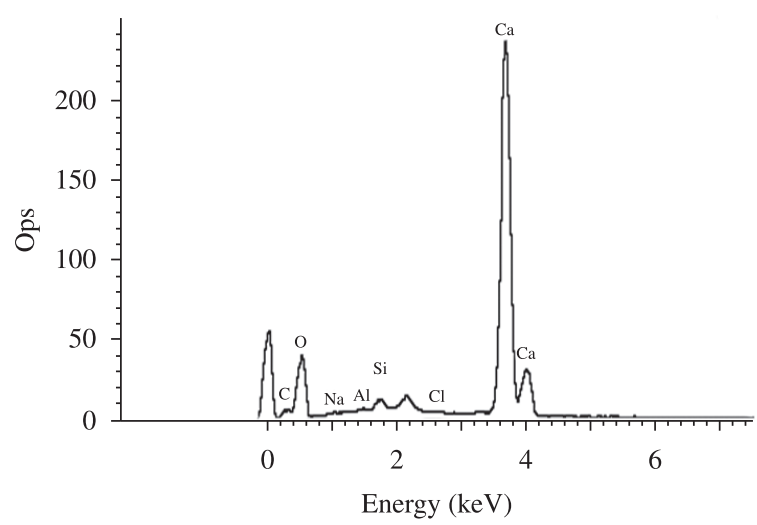

(d)

Figure 8. SEM micrographs and EDS of fracture surface region of Portland cement mortars containing $10 \mathrm{wt} .(\%)$ leather shaving treated in basic medium concentration 1:6 (reagent:water). a) Fibrous C-S-H phase and ettringite crystals; c) portlandite plates; and b, d) microanalysis. 


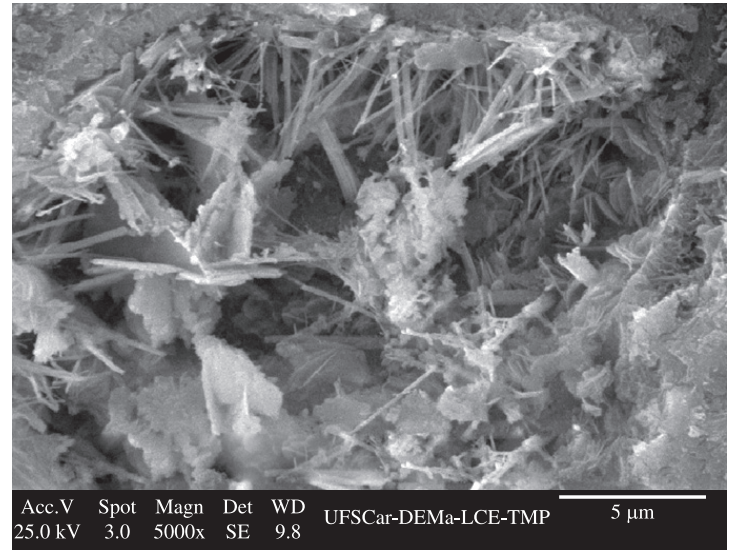

(a)

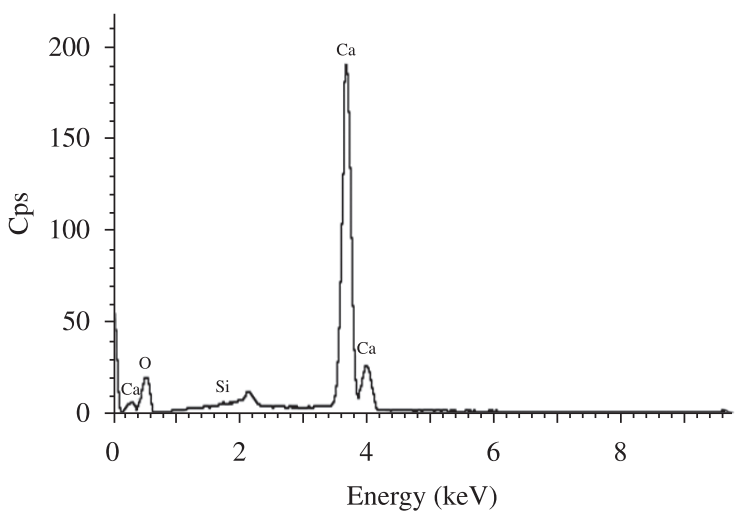

(b)

Figure 9. SEM micrographs and EDS of fracture surface region of Portland cement mortars containing $10 \mathrm{wt} .(\%)$ leather shaving treated in neutral medium concentration 1:6 (reagent:water). a) C-S-H phase, ettringite crystals, and portlandite plates; and b) microanalysis.

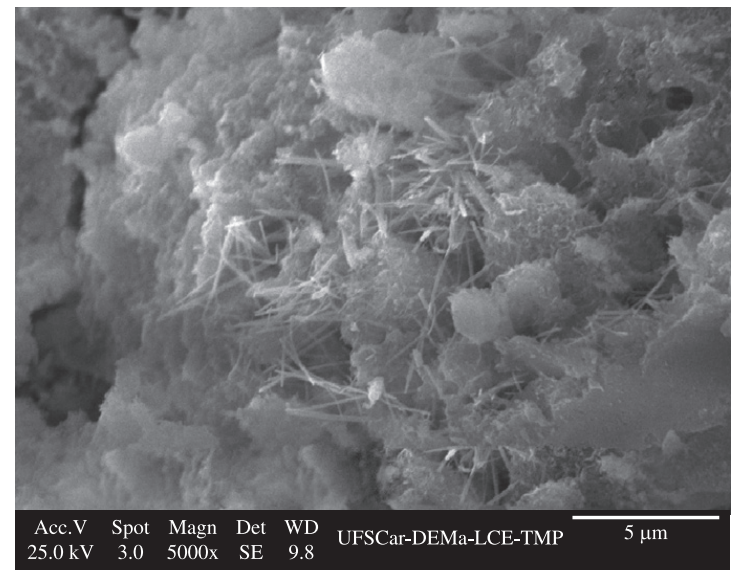

(a)

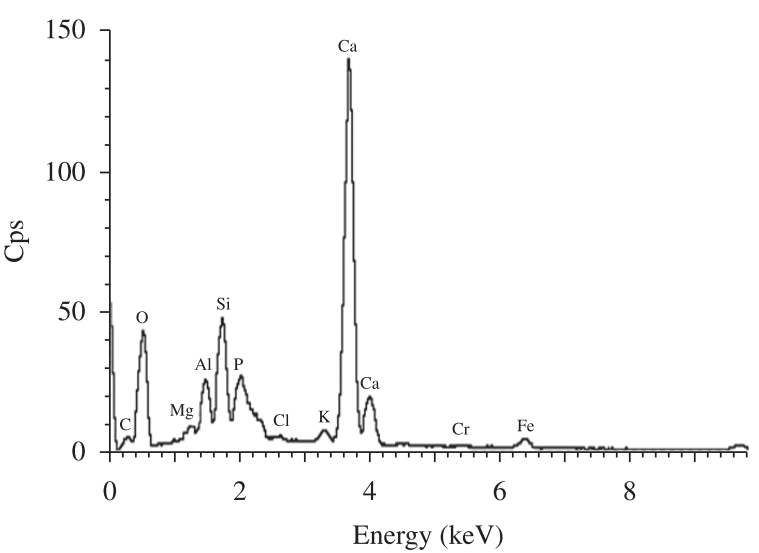

(b)

Figure 10. SEM micrographs and EDS of fracture surface region of Portland cement mortars containing 10 wt.(\%) leather shaving treated in acid medium concentration 1:2 (reagent:water). a) C-S-H phase with ettringite crystals; and b) microanalysis.

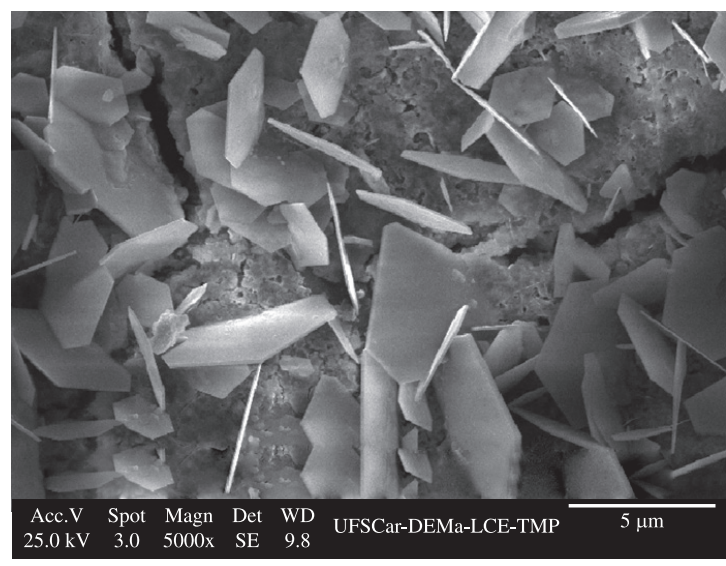

(a)

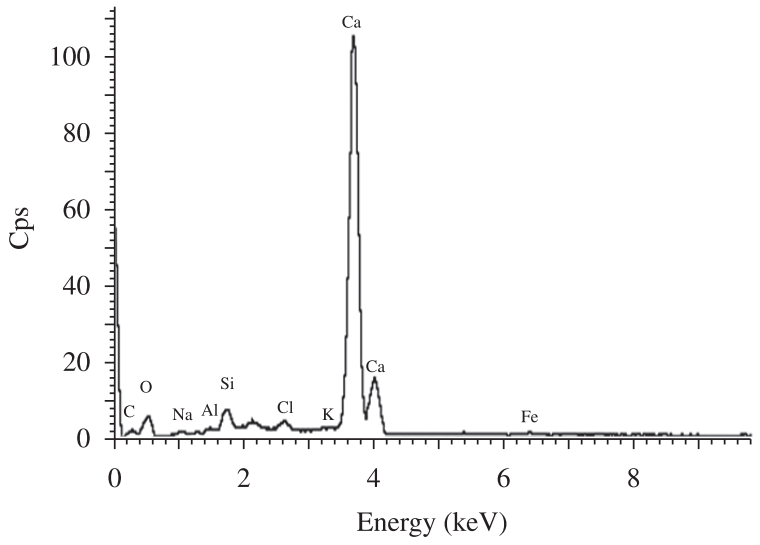

(b)

Figure 11. SEM micrographs and EDS of fracture surface region of Portland cement mortars containing $10 \mathrm{wt} .(\%)$ leather shaving treated in basic medium concentration 1:2 (reagent:water). a) Portlandite plates; and b) microanalysis. 


\subsection{Scanning Electron Microscopy (SEM) and Energy Dispersive X-ray Spectroscopy (EDS)}

The samples with the best and the worst mechanical strength results were analyzed by scanning electron microscopy (SEM) and energy dispersive X-ray spectroscopy (EDS), in order to try to identify the structures responsible for the mechanical strength of mortars and to observe the influence of different treated waste solutions in the microstructural development. The analyses in region of fracture were performed with samples selected after mechanical strength testing. The micrographs can be seen in Figure 6.

The Portland cement mortars prepared with leather shaving treated solutions proved porous with heterogeneous and complex structures. From the micrographs present in Figure 6, it is possible to observe that the surface of mortar containing waste treated in basic medium (Figure 6b) has smaller grains when compared with other surfaces, ie, hydration occurred more slowly. This same result was obtained by Lemos ${ }^{9}$, which verified if a sample is contaminated with a base not present the $\mathrm{C}_{3} \mathrm{~A}$ phase, which is one of the phases that favor the fast setting time.

The micrograph obtained in fracture surface region of mortar containing $10 \mathrm{wt} .(\%)$ leather shaving treated in acidic medium (concentration 1:6) is shown in Figure 7. In the micrograph, it is possible see the fibrous $\mathrm{C}-\mathrm{S}-\mathrm{H}$ phase, in addition to ettringite which crystallizes in the beginning of setting time in needles form and is distributed throughout the matrix, characterizing the evolution of the Portland cement hydration (Figure 7a).

The micrographs of two regions of fracture surface region of mortar containing 10 wt. $(\%)$ leather shaving treated in basic medium (concentration 1:6) show two distinct structures (Figure 8). In Figure 8a the C-S-H phase is visualized and is responsible for the mechanical strength, Acicular ettringite crystals are showed too. In Figure 8c, portlandite plates $\left(\mathrm{Ca}(\mathrm{OH})_{2}\right)$ are present around a dense matrix.

The micrographs of fracture surface region of mortar containing $10 \mathrm{wt} .(\%)$ leather shaving treated in neutral medium (concentration 1:6) are presented in Figure 9. The structure observed is a combination of the principal hydration stages, ie, it consists mainly of an array of C-S-H phase and portlandite plates, whose EDS analysis shows the main components (calcium and silicon).

Samples with a bad mechanical performance compared to the reference mortar samples (without waste) were also microscopically examined, in order to elucidate any effect arising from the leather shaving treated in solutions of different $\mathrm{pH}$. Figure 10 shows the micrograph of the mortar with leather shaving treated in acid solution with higher concentration (1:2).

The mortars samples prepared with the addition of treated waste in a highly concentrated alkaline medium (1:2) were also analyzed in the fracture surface. In the micrograph shown in Figure 11, a large number of Portlandite plates can be seen. For all microstructures, the greater amount of basic solution added is associated with the portlandite plates presence, gradually decreasing the amount of ettringite crystals and the $\mathrm{C}-\mathrm{S}-\mathrm{H}$ formation, and consequently causing a decrease in mechanical strength.

\section{Conclusions}

From the research presented herein, the following conclusions can be derived:

- The leather shaving can be easily dissolved in acid $\left(\mathrm{H}_{3} \mathrm{PO}_{4}\right)$ and basic $(\mathrm{NaOH})$ media, to result in a homogeneous aqueous solution;

- Basic solutions of caustic soda $(\mathrm{NaOH})$ containing leather shaving result in specimens with lower porosity, probably due to dispersing action of sodium ion in the Portland cement particles, providing improved packaging;

- No significant changes in the mortars characteristics in the fresh and hardened states were verified, comparing the leather shaving additions of 5 or 10 wt. $(\%)$;

- The best axial compressive strength values after 28 days age were obtained by addition of diluted phosphoric acid solution (low concentration) to leather shaving;

- The addition of waste treated at low pH (phosphoric acid) minimizes the Portlandite formation and favors the calcium phosphate formation;

- The microstructures, although complex and typical of Portland cement matrices, did not reveal the presence of leather shaving (solid), which demonstrates the chemical pre-treatment effectiveness, and can mean an alternative to the incorporation of this waste to cement composites.

\section{Acknowledgements}

The authors wish to thank the CNPq - National Counsel of Technological and Scientific Development (Brazil), PPGCEM/UFSCar - The Postgraduate Program in Materials Science and Engineering at the Federal University of São Carlos (Brazil). 


\section{References}

1. Centro das Indústrias de Curtumes do Brasil - CICB. Available from: $<\mathrm{http}: / / \mathrm{www}$.brazilianleather.com.br $>$. Access in: $15 / 07 / 2011$.

2. Tachard ALRS. Avaliação da Resistência Mecânica de Argamassas de Cimento Portland Contendo Serragem de Couro Tratada em Meio Ácido. [Tese]. São Carlos: Federal University of São Carlos; 2006. 121 p.

3. Fujikawa ES. Incorporação do resíduo "serragem cromada" em materiais de construção civil. [Tese]. Bauru: University of São Paulo State; 2002. 80 p.

4. Conner JR and Hoeffner SL. A Critical Review of Stabilization/Solidification Technology. Environmental Science and Technology. 1998; 28(4):397-462. http://dx.doi. org/10.1080/10643389891254250

5. Pacheco JWF. Curtumes. São Paulo; 2005. p. 48. Série $\mathrm{P}+\mathrm{L}$ - CETESB.

6. Wang $\mathrm{S}$ and Vipulanandan C. Solidification/stabilization of $\mathrm{Cr}$ (VI) with cement. Leachability and XRD analyses. Cement and Concrete Research. 2000; 30:385-389. http://dx.doi. org/10.1016/S0008-8846(99)00265-3
7. Palomo A and Palacios M. Alkali-activated cementious materials: Alternative matrices for the immobilization of hazardous wastes. Part II. Stabilization of chromium and lead. Cement and Concrete Research. 2003; 33:289-295. http:// dx.doi.org/10.1016/S0008-8846(02)00964-X

8. Filibeli A, Buyukkamaci N and Senol H. Solidification of tannery wastes. Resources, Conservation \& Recycling. 2000; 29:251-261.

9. Lemos RG. Estudo do comportamento hidráulico, mecânico e químico de barreiras hidráulicas verticais, compostas por solo residual, bentonita e cimento sob ação de substâncias agressivas. [Tese]. Porto Alegre: Federal University of Rio Grande do Sul; 2006. 141 p.

10. Nazari A. and Riahi S. Computer-aided prediction of physical and mechanical properties of high strength cementitious composite containing $\mathrm{Cr}_{2} \mathrm{O}_{3}$ nanoparticles. Nano, 2010; 5(5):301-318. http://dx.doi.org/10.1142/S1793292010002219

11. Nazari A. and Riahi S. The effects of $\mathrm{Cr}_{2} \mathrm{O}_{3}$ nanoparticles on strength assessments and water permeability of concrete in different curing media, Materials Science and Engineering A. 2011; 528:1173-1182. http://dx.doi.org/10.1016/j. msea.2010.09.099 